\title{
Immune responses of Holstein and Jersey calves during the preweaning and immediate postweaned periods when fed varying planes of milk replacer
}

\author{
M. A. Ballou ${ }^{1}$ \\ Department of Animal Science and Food Sciences, Texas Tech University, Lubbock 79409
}

\begin{abstract}
The objective was to determine the influence of breed and planes of preweaned milk replacer (MR) nutrition on the immune responses of pre- and postweaned dairy calves. Forty-two bull calves $(\mathrm{n}=20$ Holstein and $\mathrm{n}$ $=22$ Jersey, $2 \pm 1 \mathrm{~d}$ old) were studied. Holstein and Jersey calves came from separate dairies. Calves were fed either a higher plane of MR nutrition or a lower plane of MR nutrition. Holstein and Jersey calves on the lower planes of MR nutrition were fed $454 \mathrm{~g}$ (as fed)/d of a $20 \%$ crude protein (CP) $/ 20 \%$ fat MR. Holstein calves on the higher plane of MR nutrition were fed 810 and 1,180 g (as fed)/d of a $28 \% \mathrm{CP} / 20 \%$ fat MR for wk 1 and wk 2 to 6 , respectively. Jersey calves on the higher plane of nutrition were fed 568 and $680 \mathrm{~g}$ (as fed)/d of a $28 \% \mathrm{CP} / 25 \%$ fat MR for wk 1 and wk 2 to 6 , respectively. On d 4, 42, and 77 , peripheral blood was collected for ex vivo immunological analyses, and on d 7 all calves were challenged subcutaneously with commercially available lipopolysaccharide (LPS) from Escherichia coli (4 $\mu \mathrm{g} / \mathrm{kg}$ of body weight); clinical and biochemical responses were evaluated at $0,1,2,3,4,5$, $6,9,12,24$, and $72 \mathrm{~h}$. We observed a breed difference in total serum protein, wherein Jersey calves had higher concentrations than Holsteins. Holsteins and calves fed the higher plane of MR nutrition had greater glucose concentrations following the LPS challenge. With the exception of plasma haptoglobin concentrations at $24 \mathrm{~h}$ postchallenge, we observed no treatment $\times$ time interactions following the LPS challenge. Calves fed higher planes of MR nutrition had greater plasma haptoglobin concentrations $24 \mathrm{~h}$ following the LPS challenge. Isolated mononuclear cells from Holstein calves secreted more tumor necrosis factor- $\alpha$ than did cells from Jersey calves when stimulated ex vivo with LPS on d 77. In addition, when whole blood was incubated with a live enteropathogenic E. coli culture, blood from Holsteins
\end{abstract}

Received June 23, 2012.

Accepted September 4, 2012.

${ }^{1}$ Corresponding author: michael.ballou@ttu.edu had a greater killing capacity than did whole blood from Jerseys. Calves fed higher planes of MR nutrition had greater neutrophil oxidative burst intensities at d 77 when cocultured with $E$. coli for $10 \mathrm{~min}$. In addition, Jersey calves fed the lower plane of MR nutrition had reduced neutrophil oxidative burst capacity and whole blood E. coli killing at d 77 compared with the other groups. These data indicate that Jersey calves had lower measures of many innate immune variables despite likely having greater passive transfer, as evidenced by greater total serum protein concentrations. Furthermore, feeding a higher plane of MR nutrition to Jersey calves improved some postweaning innate immune responses.

Key words: breed, calf, immune, nutrition

\section{INTRODUCTION}

Over the past decade, interest has increased in feeding dairy calves higher planes of milk replacer (MR) during the preweaned period (Brown et al., 2005; Drackley, 2008). Before this, preweaning milk feeding programs were designed to stimulate starter intake; to do so, the quantity of milk or MR offered was restricted. The benefit of these programs was decreased overall rearing costs during the preweaning period; however, the immunological or future effects on performance are unknown. To offset the increased cost of raising calves by feeding higher planes of MR nutrition, the calves must have improved resistance to disease, earlier age to calving, or improved lactational performance later in life. The influences of various planes of MR nutrition on immune competence and health of pre- and postweaned dairy calves are not well understood (Pollock et al., 1994; Nonnecke et al., 2003; Foote et al., 2005, 2007).

Holsteins comprise over $90 \%$ of the dairy cattle in the United States. Jersey cattle are second in popularity, mainly because of their high milk solids (NAHMS, 2007). Therefore, most data on calf morbidity and mortality collected by the United States Department of Agriculture-Animal and Plant Health Inspection Service (USDA-APHIS) Animal Health and Monitor- 
ing surveys are from Holsteins (NAHMS, 2007). When those data were compared with a survey of Jersey herds (Bascom, 2002), Jersey calves had lower mortality during the first $48 \mathrm{~h}$ and through weaning. Extensive data on breed differences in immune responses are not available and are limited to cows (Bannerman et al., 2008a,b). Data from Ballou et al. (2008) indicated that Jersey calves challenged with purified LPS from Salmonella typhimurium at a subcutaneous dose of $4 \mu \mathrm{g} / \mathrm{kg}$ of BW elicited an aggressive proinflammatory response, which consequently resulted in severe hypoglycemia and $10 \%$ mortality. Similar doses of purified LPS from Escherichia coli in Holsteins administered subcutaneously at 1 and $8 \mu \mathrm{g} / \mathrm{kg}$ of BW did not elicit as strong of a response, as evidenced by the lesser degree of hypoglycemia observed (Deluyker et al., 2004). To my knowledge, no data on the innate immune responses, including responses to purified endotoxin, of Holstein and Jersey calves are available. Identifying breedspecific differences in innate immune responses would allow management, pharmacological, and therapeutic strategies to be implemented on a breed-specific basis.

The first hypothesis in the current study was that feeding a higher plane of MR nutrition would improve the innate immune responses of calves, irrespective of breed. The second hypothesis was that Jersey calves would have reduced neutrophil oxidative burst and whole-blood bactericidal capacities but an exacerbated inflammatory response. To test these hypotheses, the innate immune responses of Holstein and Jersey calves fed either low or high planes of MR nutrition were evaluated.

\section{MATERIALS AND METHODS}

\section{Experimental Design, Calves, and Diets}

All animal procedures were approved by the Animal Care and Use Committee at Texas Tech University. The animal work was conducted from June to August 2009. Average relative humidity and low and high temperatures over the experimental period were $44 \%, 19.6^{\circ} \mathrm{C}$, and $34.3^{\circ} \mathrm{C}$, respectively. Forty-two bull calves $(\mathrm{n}=20$ Holstein; $\mathrm{n}=22$ Jersey) were acquired from 2 local commercial dairy herds. Calves were $2 \pm 1 \mathrm{~d}$ of age when enrolled into the study and, within each breed, randomly assigned to either a low plane or high plane of MR nutrition. The chemical compositions and feed ingredients used in the formulations of all the MR are reported in Table 1. Holstein and Jersey calves on the lower planes of MR nutrition (Holstein-Low and JerseyLow, respectively) were fed $454 \mathrm{~g} / \mathrm{d}$ (as fed) of a $20 \%$ CP, $20 \%$ lipid MR at 10.4\% solids DM (Herd Maker,
Land O'Lakes Animal Milk Protein Co., Shoreview, MN). Holstein calves on a higher plane of MR nutrition (Holstein-High) were fed 810 and 1,180 g/d (as fed) of a $28 \%$ CP, $20 \%$ lipid MR at 14.9 and $15.5 \%$ solids DM (Cow's Match, Land O'Lakes Animal Milk Protein Co.) in wk 1 and wk 2 to 6 , respectively. Jersey calves on higher plane of MR nutrition (Jersey-High) were fed 568 and $680 \mathrm{~g} / \mathrm{d}$ (as fed) of a $28 \% \mathrm{CP}, 25 \%$ lipid MR at $11.4 \%$ solids DM (Cow's Match Jersey Blend, Land O'Lakes Animal Milk Protein Co.) for wk 1 and wk 2 to 6 , respectively. The lower planes of nutrition are more typical of restricted MR feeding programs, whereas the higher planes of nutrition are close to ad libitum intakes during the first month of life. All MR used in the current study are commercially available. The Herd Maker formulation is recommended to be fed at lower planes of nutrition, and the Cow's Match formulations are recommended to be fed at higher planes of nutrition. Jersey-Low calves were fed more $\mathrm{MR}$ as a percentage of metabolic BW $\left(\mathrm{BW}^{0.75}\right)$ than Holstein-Low calves, and Jersey-High calves were fed MR with more fat and ME per kilogram of DM than Holstein-High because Jersey calves may require more energy per $\mathrm{BW}^{0.75}$ as shown by the fact that Jersey calves gained less BW than expected according to the NRC (2001) for calves fed MR only (Ballou and DePeters, 2008). All MR were medicated with oxytetracycline and neomycin base. The concentrations of oxytetracycline were 137, 110, and $146 \mathrm{mg} / \mathrm{kg}$ for the Herd Maker, Cow's Match, and Cow's Match Jersey Blend MR, respectively. The concentrations of neomycin base were 275, 220, and 293 $\mathrm{mg} / \mathrm{kg}$ for the Herd Maker, Cow's Match, and Cow's Match Jersey Blend MR, respectively. Calves were fed MR from bottles twice daily at 0730 and $1630 \mathrm{~h}$. All calves were offered ad libitum access to common calf starter (Table 2) and water following the first week.

All Holstein calves came from a single dairy; likewise, all Jersey calves came from a single, different dairy. Therefore, the breed effect cannot be completely differentiated from a potential dairy effect. All calves were fed $4 \mathrm{~L}$ of pooled colostrum from their respective dairy within $8 \mathrm{~h}$ of birth. Dry-cow vaccination programs between the 2 dairies were similar.

Peripheral blood samples were collected into evacuated tubes without any additive at enrollment and analyzed for total serum protein using a handheld refractometer. A total protein concentration of $5.2 \mathrm{~g} / \mathrm{dL}$ was used as the cut-off to determine the proportion of calves that had failure of passive transfer of immunoglobulin, based on information from Tyler et al. (1996), who developed a regression equation where a total serum protein concentration of $5.2 \mathrm{~g} / \mathrm{dL}$ was equivalent to $1,000 \mathrm{mg} / \mathrm{dL}$ of serum $\operatorname{IgG}_{1}$. All calves were housed 
Table 1. Chemical composition of milk replacers (MR) fed at a low plane of nutrition or a high plane of nutrition ${ }^{1}$

\begin{tabular}{lccc}
\hline & & \multicolumn{2}{c}{ High-plane MR } \\
\cline { 3 - 4 } Chemical composition & Low-plane MR & Holstein & Jersey \\
\hline DM, \% & 97 & 97 & 97 \\
CP, \% DM & 20.6 & 28.8 & 28.8 \\
Fat, \% of DM & 21 & 20.6 & 25.8 \\
ME, Mcal/kg of DM & 4.65 & 4.75 & 5.05 \\
Calcium, \% of DM & 1.03 & 1.03 & 1.03 \\
Phosphorus, \% of DM & 0.72 & 0.72 & 0.72 \\
Vitamin A, kIU/kg of DM & 44 & 44 & 44 \\
Vitamin D, kIU/kg of DM & 11 & 11 & 11 \\
Vitamin E, IU/kg of DM & 220 & 220 & 275 \\
\hline
\end{tabular}

${ }^{1}$ All milk replacers were formulated with the same ingredients, including dried whey, dried whey protein concentrate, dried whey product, dried skim milk, dried milk protein, and edible lard (Land O'Lakes Animal Milk Products Co., Shoreview, MN).

individually in commercial $2.13-\times 1.09-\mathrm{m}$ polyethylene calf hutches (Agri-Plastics, Tonawanda, NY) attached to a $1.83-\times 1.09-m$ open-air pen. The calf hutches were bedded with loose straw.

Individual calf BW were recorded at enrollment and at $7,14,28,42$, and $77 \mathrm{~d}$ of the study period. On d 42 of the study period, afternoon feedings were removed to encourage starter consumption. Calves were completely weaned off milk when they consumed at least $900 \mathrm{~g} / \mathrm{d}$ (as fed) of calf starter for 2 consecutive days after removal of afternoon feeding.

Fecal scores were classified by 2 independent trained observers multiple times daily according to the guidelines outlined by Larson et al. (1977). Briefly, 1 = firm, well-formed (not hard); $2=$ soft, pudding-like; $3=$ runny, pancake batter; and $4=$ liquid, splatters, pulpy orange juice. Data for each calf were averaged over 3-d periods before statistical analysis.

Table 2. Ingredient and chemical compositions of calf starter

\begin{tabular}{lc}
\hline Item & Value \\
\hline Ingredient, \% of DM & \\
Steam-flaked sorghum & 52.7 \\
Canola meal pellet & 23.0 \\
Sweet bran & 14.0 \\
Molasses & 7.5 \\
Vitamin/mineral premix ${ }^{2}$ & 2.8 \\
Chemical composition & 81.7 \\
DM, \% & 18.8 \\
CP, \% & 3.03 \\
ME, Mcal/kg &
\end{tabular}

${ }^{1}$ Sweet bran (Cargill Inc., Minneapolis, MN) is a corn gluten feed product made from the ingredients of the corn wet milling process.

${ }^{2}$ Premix contained (DM basis) $52.6 \%$ limestone; $39.9 \%$ soybean meal; $6 \%$ salt; $0.451 \%$ zinc sulfate; $0.4 \%$ selenium selenite $0.2 \% ; 0.267 \%$ manganese oxide; $0.18 \%$ vitamin E, $500 \mathrm{IU} / \mathrm{g} ; 0.157 \%$ copper sulfate; $142 \mathrm{mg} / \mathrm{kg}$ of vitamin A, $1,000 \mathrm{kIU} / \mathrm{g} ; 12.5 \mathrm{mg} / \mathrm{kg}$ of ethylenediamine dihydroiodide; $8.7 \mathrm{mg} / \mathrm{kg}$ of cobalt carbonate.

\section{LPS Challenge}

On $\mathrm{d} 7$ following the initiation of dietary treatments, each calf was injected subcutaneously immediately posterior to the scapula with $4 \mu \mathrm{g} / \mathrm{kg}$ of BW of Escherichia coli 0111:B4 LPS (Sigma-Aldrich Co., St. Louis, MO) at $0700 \mathrm{~h}$. The LPS was reconstituted with nonpyrogenic PBS and confirmed to be free of bacterial contamination by plating the LPS preparation on blood agar plates. Calves were not fed during the first $12 \mathrm{~h}$ of data collection in order to limit any confounding postprandial metabolic changes (Hüsier and Blum, 2002; Ballou et al., 2008). Calves were offered $2 \mathrm{~L}$ of an acidified oral electrolyte solution at $1400 \mathrm{~h}$ to prevent dehydration (Bluelite C, Tech Mix, Stewart, MN).

\section{Observations and Sampling}

General attitude, appetite, and rectal temperature were assessed immediately before and at 1, 2, 3, 4, 5, 6, $8,10,12,24,48$, and $72 \mathrm{~h}$ after LPS challenge. Attitude was classified as $1=$ normal, alert, response to stimuli quick; 2 = depressed, response to stimuli decreased; 3 $=$ lethargic, response to stimuli greatly reduced; $4=$ morbid, little or no response to stimuli. The observer's fingers were used to measure the suckling response of each calf as a measure of appetite. Appetite was classified as $0=$ normal, strong suckle reflex; $1=$ moderately anorectic, weak suckle reflex, licks finger; and 2 $=$ completely anorectic, no suckle reflex or interest in the observer's finger. Hands were washed in between assessing calves for appetite. All attitude and appetite data were collected by a single observer blinded to the plane of nutrition treatment. Rectal temperatures were taken with a single thermometer that was calibrated before the challenge and cleaned between calves (M700 Digital Thermometer, GLA Agricultural Electronics, 
San Luis Obispo, CA). Approximately $13 \mathrm{~mL}(10 \mathrm{~mL}$ for biochemical analyses and $3 \mathrm{~mL}$ for hematology) of peripheral blood was collected into evacuated EDTA tubes at each time point by jugular venipuncture. The $10-\mathrm{mL}$ tube was centrifuged $(1,500 \times g$ for $20 \mathrm{~min})$ within 25 min of collection and plasma was stored at $-40^{\circ} \mathrm{C}$ until subsequent analyses.

\section{Blood Analyses}

Within $2 \mathrm{~h}$ of blood collection, whole blood was analyzed for total leukocyte counts and differential analyses of neutrophils and mononuclear cells using a Cell Dyn 3700 (Abbott Laboratories, Abbott, IL) with a veterinary software package. The settings on the Cell Dyn 3700 specific for bovine blood did not allow further differentiation of mononuclear cells into lymphocytes and monocytes; therefore, data are reported as total mononuclear cells. Plasma glucose and urea nitrogen were analyzed using commercially available enzymatic kits (Stanbio Laboratory, Boerne, TX). All procedures were followed per the manufacturer's instructions for the manual method; however, sample and reagent volumes were scaled for use in 96-well microplates. Normal control serum (Randox Laboratories, Crumlin, UK) was used to calculate the interassay coefficients of variation for plasma glucose and urea nitrogen, which were 4.2 and $5.1 \%$, respectively. Intraassay coefficients of variations were 3.7 and $4.8 \%$ for plasma glucose and urea nitrogen, respectively. Plasma NEFA concentrations were measured as described previously by Ballou et al. (2009) with intra- and interassay coefficients of variation of 4.2 and $5.5 \%$, respectively. Plasma haptoglobin was quantified as described by Makimura and Suzuki (1982). A pooled plasma sample was used to calculate the interassay coefficient of variation of $1.8 \%$ for the haptoglobin assay. All colorimetric data were measured on a SpectraMax 340PC (Molecular Devices, Sunnyvale, CA).

\section{Ex Vivo Immunological Analyses}

On d 42 and 77, peripheral blood mononuclear cells were isolated by density centrifugation and enumerated as previously described (Ballou et al., 2009). Peripheral blood mononuclear cells were resuspended at $2 \times 10^{6}$ cells/mL in RPMI-1640 medium at a final concentration of $10 \%$ autologous plasma and $1 \%$ penicillin/streptomycin. Cell suspensions were resuspended at a final concentration with $5 \mathrm{ng} / \mathrm{mL}$ recombinant bovine IFN- $\gamma$ (rIFN- $\gamma$; Endogen, Rockport, IL) and either 0, 0.01, or $5 \mu \mathrm{g} / \mathrm{mL}$ of LPS (E. coli 0111:B4; Sigma, St. Louis, $\mathrm{MO}$ ). Cell suspensions were incubated for $24 \mathrm{~h}$ at $37^{\circ} \mathrm{C}$ in a humidified $5 \% \mathrm{CO}_{2}$ incubator. After centrifugation at $1,200 \times g$ for $15 \mathrm{~min}$, supernatant was removed and stored at $-40^{\circ} \mathrm{C}$ until analysis for concentrations of tumor necrosis factor- $\alpha$ (TNF- $\alpha$ ) using a commercially available ELISA kit (Endogen).

Additional cell cultures to evaluate the responsiveness of mononuclear cells to T-lymphocyte mitogens were conducted. Briefly, mononuclear cells were resuspended as described above but stimulated with either $5 \mu \mathrm{g} / \mathrm{mL}$ concanavalin-A (Sigma) or $10 \mu \mathrm{g} / \mathrm{mL}$ phytohemagglutinin-P (Sigma) instead of rIFN- $\gamma$ and LPS. The cell suspensions were incubated for $72 \mathrm{~h}$ at $37^{\circ} \mathrm{C}$ in a humidified $5 \% \mathrm{CO}_{2}$ incubator. After centrifugation, supernatant was removed and stored at $-40^{\circ} \mathrm{C}$ until analyzed for concentrations of IFN- $\gamma$ by a commercially available ELISA kit (Endogen).

On d 4, 42, and 77, a whole-blood oxidative burst assay was conducted (Smits et al., 1997). The immunogenic stimulus was a heat-killed enteropathogenic $E$. coli (Hulbert et al., 2011). Two incubation times, 10 and $60 \mathrm{~min}$, were determined before initiation of the study. The 10-min incubation was used to indicate the rate of the oxidative burst reaction, whereas the 60 min incubation reflects the maximal capacity of the reaction. All data were analyzed on a Cell Lab Quanta SC flow cytometer (Beckman Coulter, Fullerton, CA). Neutrophil populations were gated according to size and side-scatter characteristics of the cell population. Data are reported as the geometric mean fluorescence intensities of the neutrophil populations that were positive for producing an oxidative burst.

On d 4, 42, and 77, we evaluated the ability of whole blood to kill a live culture of the $E$. coli strain used in the oxidative burst assay. Briefly, an overnight broth culture of the $E$. coli was diluted in nonpyrogenic $1 \times$ PBS to an approximate concentration of $25 \mathrm{cfu} / \mu \mathrm{L}$ and kept in an ice bath. Whole blood was diluted 1:2 with RPMI-1640 to a final volume of $200 \mu \mathrm{L}$. All tubes were placed in an ice bath for $15 \mathrm{~min}$. Then, $20 \mu \mathrm{L}$ of the working $E$. coli culture was added to each tube of diluted whole blood, vortexed, and incubated in a recirculating water bath at $38.5^{\circ} \mathrm{C}$ for either 10 or 60 min, which corresponded to the incubation times used in the oxidative burst assay. Following incubation, the cultures were vortexed, $50 \mu \mathrm{L}$ of each culture was pipetted and spread plated onto tryptic soy agar plates in duplicate, and the plates were incubated overnight before determination of the number of colony-forming units. Data are expressed as the percentage of killing, calculated by plating the diluted working $E$. coli culture in $200 \mu \mathrm{L}$ of RPMI-1640 only. The sampling days of 4 , 42 , and 77 were chosen because they reflect the neonatal period, immediate preweaning, and postweaning periods, respectively. 


\section{Statistical Analyses}

All repeated continuous data were analyzed by restricted-maximum likelihood ANOVA using the Mixed procedure of SAS (version 9.2; SAS Institute Inc., Cary, NC). A linear, mixed model with the fixed effects of treatment and time and their interaction was fitted. The random effect was calf nested within treatment. The mean model was run with all available covariance structures for the within-subject measurement. The appropriate covariance structure for was chosen for each analysis based on the Schwarz Bayesian information criterion. Degrees of freedom for $F$-tests of the fixed effects were estimated using Kenward-Rogers approximation. Normality of the residuals was confirmed by evaluating the Shapiro-Wilk statistic using the Univariate procedure of SAS (version 9.2; SAS Institute Inc.). Preplanned contrasts for breed (Holstein-Low and Holstein-High vs. Jersey-Low and Jersey-High), plane of MR nutrition (Holstein-Low and Jersey-Low vs. Holstein-High and Jersey-High), and breed $\times$ plane of MR nutrition interaction (Holstein-Low and Jersey-High vs. Holstein-High and Jersey-Low) were performed for each treatment and treatment $\times$ time interaction.

The repeated ordinal variables (attitude and appetite) were analyzed by generalized estimating equations with a multinomial distribution using the GenMod procedure of SAS (version 9.2; SAS Institute Inc.). Calf was the repeated unit, and the independent covariance structure was used to fit the model. The model included treatment, time, and the interaction of treatment and time. Least squares means $( \pm \mathrm{SEM})$ are reported throughout. Treatment difference of $P \leq 0.05$ was considered significant and $0.05<P \leq 0.10$ was considered a tendency.

\section{RESULTS}

\section{Calves and Performance}

Total serum protein was different between breeds at enrollment but did not differ due to plane of MR nutrition (Table 3). Furthermore, the frequency of calves with failure of passive transfer (serum total protein $\leq 5.2 \mathrm{~g} / \mathrm{dL})$ was different $(P<0.01)$ between breeds, with 62.5 and $26.3 \%$ of failure of passive transfer among Holstein and Jersey calves, respectively; however, no differences were observed within each breed in the frequency of calves with failure of passive transfer assigned to either to low or high planes of MR nutrition. Pre- and postweaning performance and intakes are shown in Table 3. The BW of calves within breed for planes of MR nutrition were not different at initia- tion of treatments. Calves fed the higher planes of MR nutrition had increased intakes of ME and $\mathrm{CP}$, which resulted in greater ADG during the preweaned period only. In addition, the intakes of both $\mathrm{ME}$ and $\mathrm{CP}$ when expressed per kilogram of metabolic BW during the preweaned period were increased among calves fed higher planes of MR nutrition, but were not different between breeds. During the postweaned period, plane of MR nutrition did not affect the intake of DM or intakes of ME and CP. However, because calves previously fed lower planes of MR nutrition had lesser BW at weaning, the postweaned intakes of DM, ME, and CP, when expressed per kilogram of metabolic BW, were greater for calves previously fed the lower planes of MR nutrition. In addition, Jersey calves consumed less DM, ME, and $\mathrm{CP}$ per kilogram of metabolic BW than Holstein calves during the postweaned period. Finally, Jersey calves in this study had consistently $(P<0.01)$ greater fecal scores during the first $21 \mathrm{~d}$ of the study compared with Holstein calves (2.47 vs. $2.07 \pm 0.083$ ).

\section{LPS: Clinical and Biochemical}

A subcutaneous challenge with $4 \mu \mathrm{g}$ of LPS/ $\mathrm{kg}$ of BW induced clinical and biochemical changes consistent with an activated acute phase response, including sickness behavior, hyperthermia, leukopenia, and hypoglycemia in all calves. Clinical and biochemical data following the LPS challenge are reported in Table 4 . No treatment $\times$ time interactions were observed for any of the clinical or biochemical responses following the LPS challenge. A tendency $(P<0.09)$ was found for a breed $\times$ plane of MR nutrition effect on total leukocyte concentrations in peripheral blood. HolsteinHigh had greater total leukocyte concentrations than Holstein-Low, but Jersey-High and Jersey-Low did not differ from each other. In addition, breed $(P<$ $0.01)$ and plane of MR nutrition $(P<0.04)$ affected the concentrations of plasma glucose following the challenge. Holsteins and calves (irrespective of breed) fed the higher planes of MR nutrition had greater plasma glucose concentrations. A breed effect $(P<0.01)$ on blood urea nitrogen concentrations was observed, wherein Holstein calves had lower concentrations than Jersey calves. A time effect $(P<0.01)$ on plasma concentrations of the acute phase protein haptoglobin was observed. Concentrations of haptoglobin were elevated beginning at $24 \mathrm{~h}$ after the LPS challenge and remained elevated at $120 \mathrm{~h}$. Plane of MR nutrition had an effect $(P<0.05)$ at $24 \mathrm{~h}$ after the LPS challenge; Holstein and Jersey calves fed the higher planes of MR nutrition had greater haptoglobin concentrations than calves fed the lower planes of MR nutrition. 
Table 3. Initial BW, total serum protein concentrations, and pre- and postweaning performance of Holstein and Jersey calves fed different planes (low and high) of milk replacer nutrition

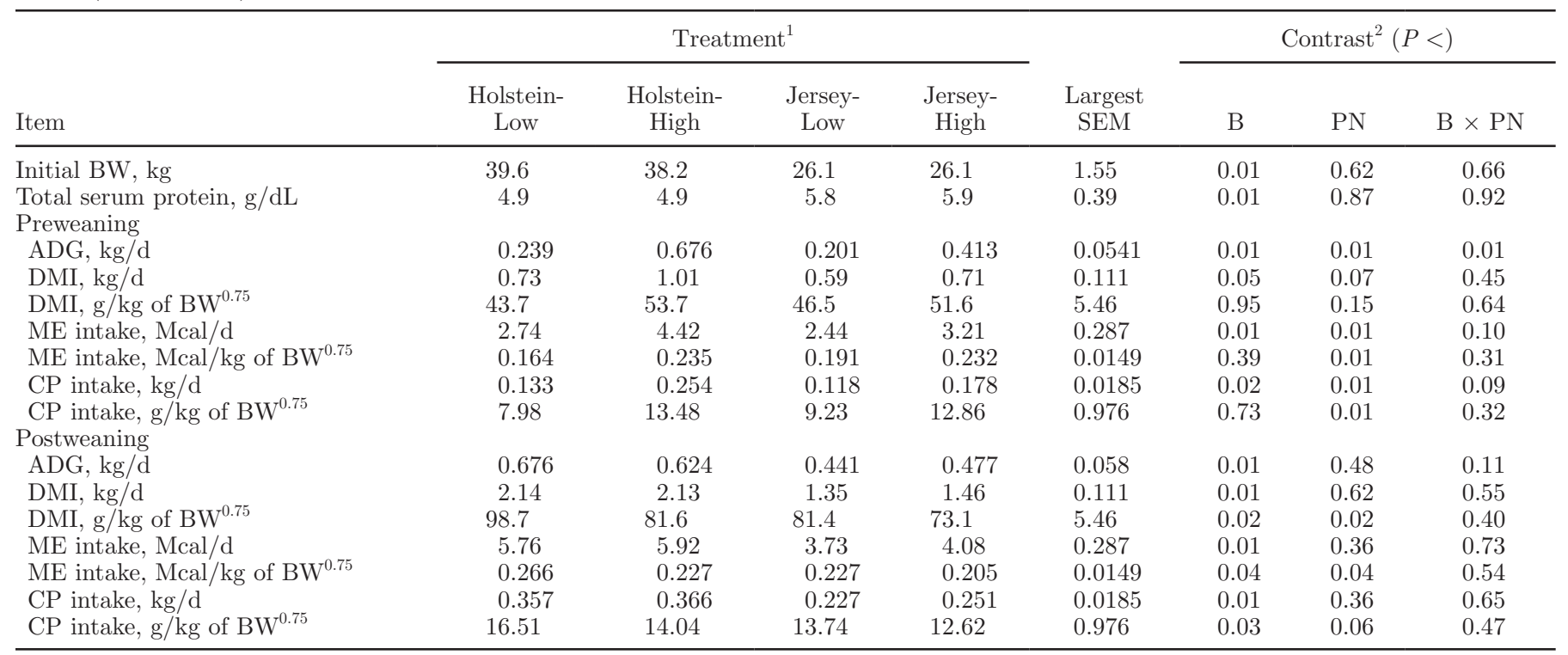

${ }^{1}$ Treatments included breed (Holstein vs. Jersey) and planes of nutrition (low vs. high). Calves fed the low plane of nutrition were fed $454 \mathrm{~g} / \mathrm{d}$ of a 20/20 milk replacer (HerdMaker, Land O'Lakes Animal Milk Products Co., Shoreview, MN). Holstein calves fed the high plane of nutrition were fed $810 \mathrm{~g} / \mathrm{d}$ of a 28/20 milk replacer (Cow's Match, Land O'Lakes Animal Milk Products Co.). Jersey calves fed the high plane of nutrition were fed $568 \mathrm{~g} / \mathrm{d}$ of a 28/25 milk replacer (Jersey Blend Cow's Match, Land O'Lakes Animal Milk Products Co.).

${ }^{2}$ Contrasts include breed $(\mathrm{B})=$ Holstein-Low and Holstein-High vs. Jersey-Low and Jersey-High; plane of nutrition $(\mathrm{PN})=$ Holstein-Low and Jersey-Low vs. Holstein-High and Jersey-High; B $\times$ PN $=$ Holstein-Low and Jersey-High vs. Holstein-High and Jersey-Low.

\section{Mononuclear Cell Culture: Cytokine Secretion}

A breed effect $(P<0.01)$ was found for the secretion of TNF- $\alpha$ from stimulated mononuclear cell cultures at d 77 (Figure 1): mononuclear cells from Holstein calves secreted more TNF- $\alpha$ than cells from Jersey calves. No differences were found between breed, plane of MR nutrition, or the interaction between breed and plane of MR nutrition on the secretion of IFN- $\gamma$ when mononuclear cell cultures were stimulated with either phytohemagglutinin-P or concanavalin-A (data not shown).

Table 4. Clinical and biochemical responses of Holstein and Jersey calves fed different planes of milk replacer nutrition following a subcutaneous LPS (4 $\mu \mathrm{g} / \mathrm{kg}$ of BW, Escherichia coli 0111:B4) challenge $7 \mathrm{~d}$ after initiation of treatments

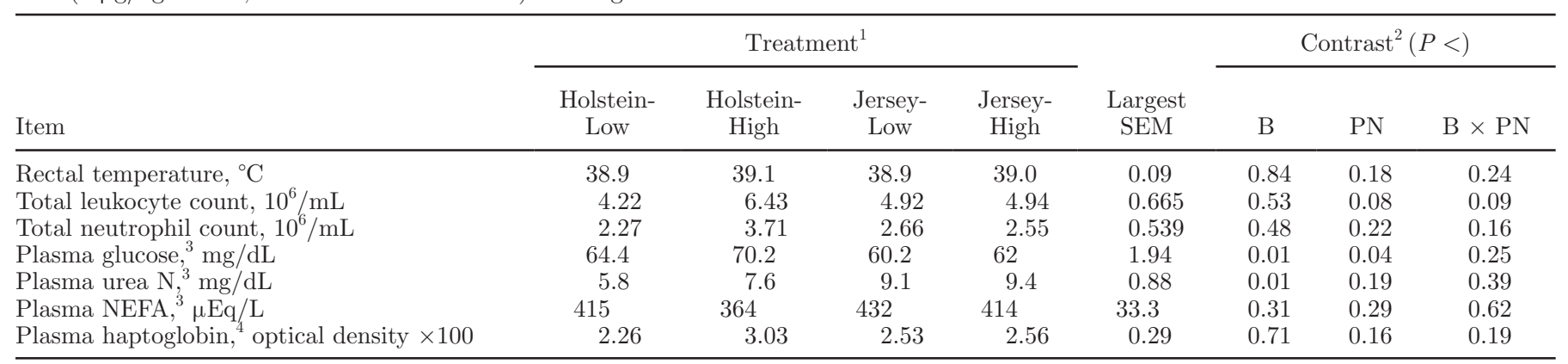

${ }^{1}$ Treatments included breed (Holstein vs. Jersey) and planes of nutrition (low vs. high). Calves fed the low plane of nutrition were fed $454 \mathrm{~g} / \mathrm{d}$ of a 20/20 milk replacer (HerdMaker, Land O'Lakes Animal Milk Products Co., Shoreview, MN). Holstein calves fed the high plane of nutrition were fed $810 \mathrm{~g} / \mathrm{d}$ of a 28/20 milk replacer (Cow's Match, Land O'Lakes Animal Milk Products Co.). Jersey calves fed the high plane of nutrition were fed $568 \mathrm{~g} / \mathrm{d}$ of a 28/25 milk replacer (Jersey Blend Cow's Match, Land O'Lakes Animal Milk Products Co.). No treatment $\times$ time interactions were observed $(P \leq 0.05)$.

${ }^{2}$ Contrasts include breed $(\mathrm{B})=$ Holstein-Low and Holstein-High vs. Jersey-Low and Jersey-High; plane of nutrition $(\mathrm{PN})=$ Holstein-Low and Jersey-Low vs. Holstein-High and Jersey-High; B $\times$ PN $=$ Holstein-Low and Jersey-High vs. Holstein-High and Jersey-Low.

${ }^{3}$ Data are reported for the 0 - to 24 -h postchallenge period.

${ }^{4}$ Data are reported for $0,12,24,72$, and $120 \mathrm{~h}$ postchallenge. We observed a sliced PN effect $(P<0.02)$ at $24 \mathrm{~h}$ after the challenge, wherein Holstein-High and Jersey-High were greater than Holstein-Low and Jersey-Low. 


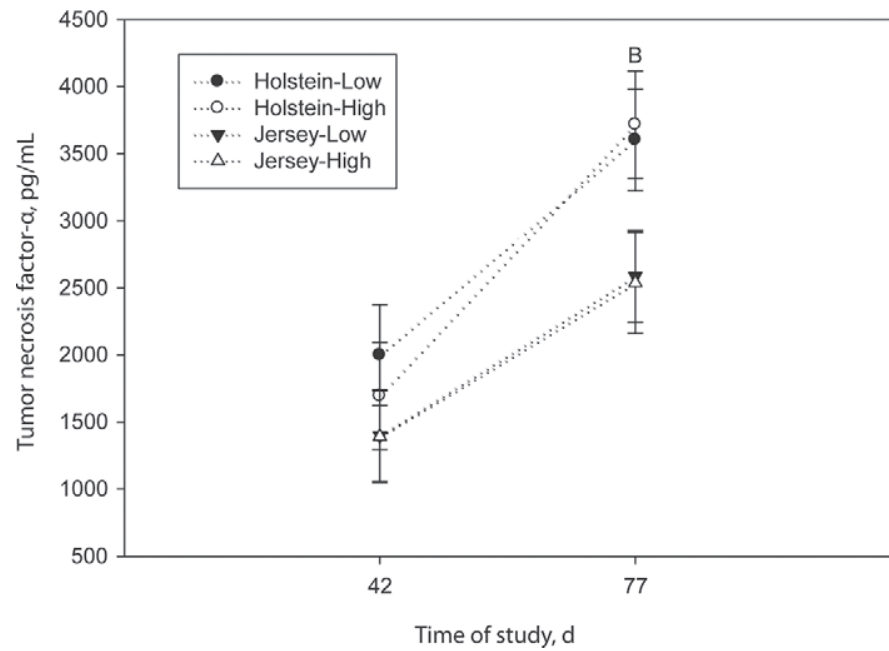

Figure 1. Secretion of tumor necrosis factor- $\alpha$ from isolated peripheral blood mononuclear cells when cocultured with LPS from Escherichia coli 0111:B4 on d 42 and 77 after initiation of treatments. Treatments included breed (Holstein vs. Jersey) and plane of nutrition (low vs. high). Calves fed the low plane of nutrition were fed $454 \mathrm{~g} / \mathrm{d}$ of a $20 \% \mathrm{CP} / 20 \%$ fat milk replacer; Holstein calves fed the high plane of nutrition were fed $810 \mathrm{~g} / \mathrm{d}$ of a $28 \% \mathrm{CP} / 20 \%$ fat milk replacer; Jersey calves fed the high plane of nutrition were fed $568 \mathrm{~g} / \mathrm{d}$ of a $28 \%$ $\mathrm{CP} / 25 \%$ fat milk replacer. Treatment, $P<0.06$; sliced breed contrast (B; Holstein-Low and Holstein-High vs. Jersey-Low and Jersey-High) at d $77, P<0.05$. Error bars represent \pm SEM.

\section{Neutrophil Oxidative Burst and Whole-Blood Killing of E. coli}

When neutrophils were incubated with the E. coli for $10 \mathrm{~min}$, there was a treatment $\times$ time interaction on the intensity of the oxidative burst response $(P<0.04$; Figure 2a). Jersey calves had a less-intense oxidative burst on both d 42 and $77(P<0.04)$ compared with Holstein calves. In addition, calves fed the higher plane of MR nutrition had a more intense oxidative burst on d 77 compared with calves fed the lower plane of MR nutrition. Whole blood from Holsteins had greater $(P$ $<0.04$; Figure 2b) E. coli killing capacity than did blood from Jersey calves on d 77 when the blood was incubated with a live culture of the $E$. coli for $10 \mathrm{~min}$.

There was an interaction between breed and plane of MR nutrition $(P<0.01)$ on neutrophil oxidative burst intensity (Figure 3a) and whole-blood killing capacity (Figure $3 \mathrm{~b}$ ) at d 77 when whole blood was cocultured with $E$. coli for $60 \mathrm{~min}$. Jersey-Low calves had lower responses than other group for both immune responses.

\section{DISCUSSION}

The influences of breed and planes of MR nutrition on health and various immune responses were investigated in pre- and postweaned Holstein and Jersey calves.
Growth rate was influenced by plane of MR nutrition during the preweaned period only. Jersey calves had higher fecal scores during the first 3 wk of life; however, the fecal microbiota was not determined in the current study, so nutritional and microbial influences on fecal consistencies cannot be differentiated. Passive transfer of immunoglobulins likely did not play a role in the higher fecal scores because Jersey calves had greater total serum protein concentrations, and fewer calves classified as having failure of passive transfer of im-
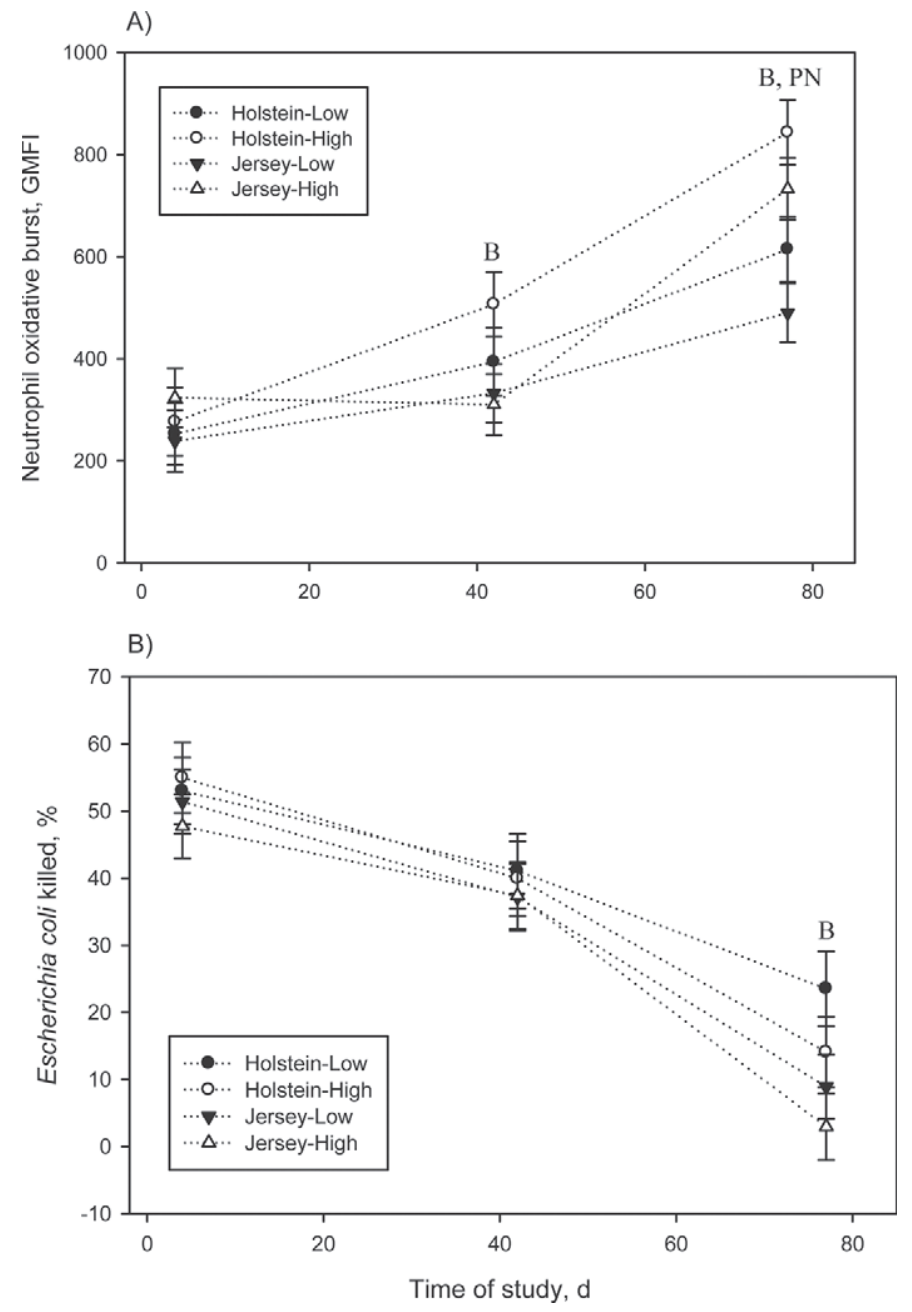

Figure 2. (a) Neutrophil oxidative burst geometric mean fluorescence intensity (GMFI) after 10 min incubation with an enteropathogenic Escherichia coli on d 4, 42, and 77 after initiation of treatments. Treatments included breed (Holstein vs. Jersey) and plane of nutrition (low vs. high). Treatment $\times$ time, $P<0.04$; sliced breed (B) contrast (Holstein-Low and Holstein-High vs. Jersey-Low and Jersey-High) at d 42 and 77, $P<0.05$; sliced plane of nutrition $(\mathrm{PN})$ contrast (HolsteinLow and Jersey-Low vs. Holstein-High and Jersey-High) at d $42, P<$ 0.01. (b) Killing capacity of whole blood when incubated for $10 \mathrm{~min}$ with an enteropathogenic Escherichia coli on d 4, 42, and 77 after initiation of treatments. Sliced breed (B) contrast (Holstein-Low and Holstein-High vs. Jersey-Low and Jersey-High) at d 77, $P<0.02$. Error bars represent \pm SEM. 
A)

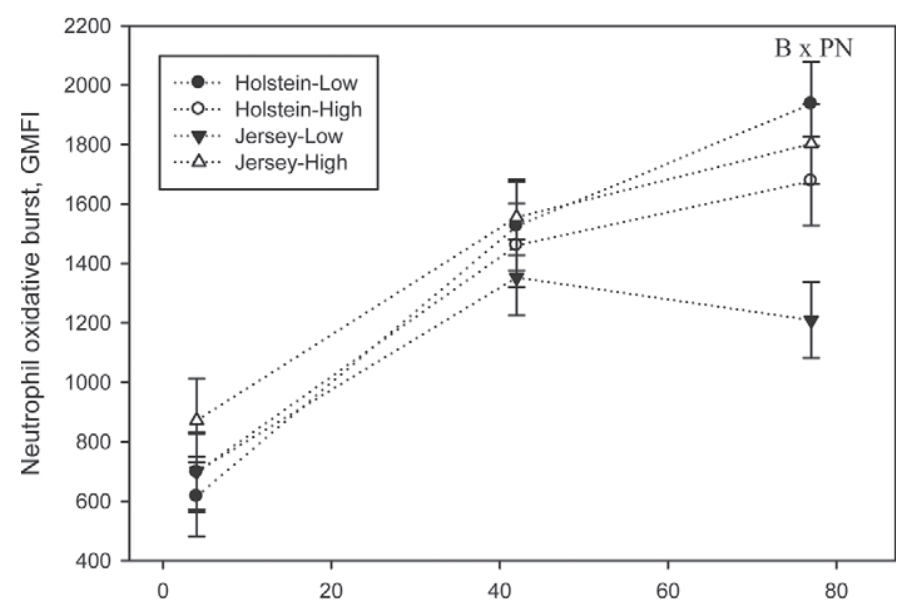

B)

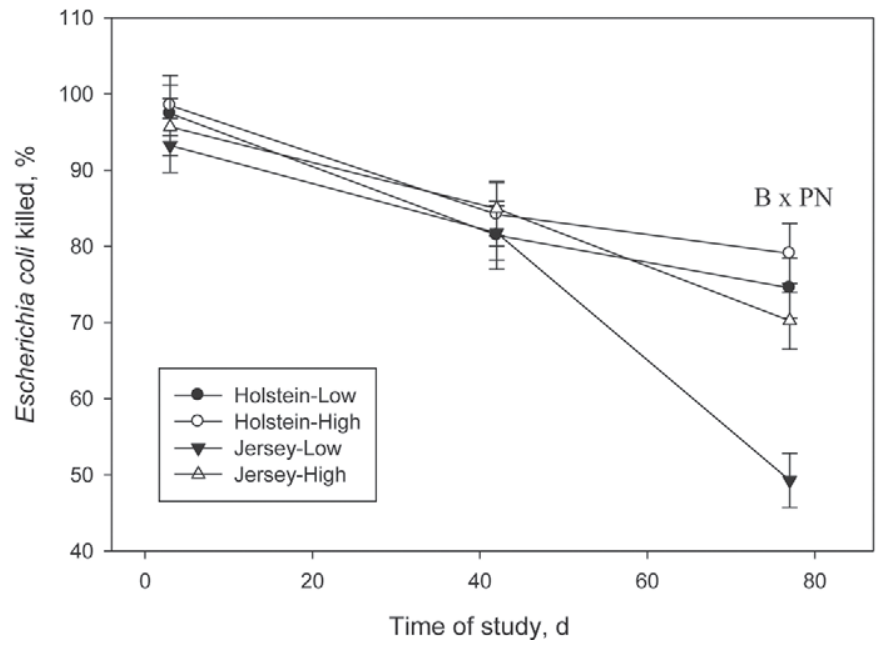

Figure 3. (a) Neutrophil oxidative burst geometric mean fluorescence intensity (GMFI) after 60-min incubation with an enteropathogenic Escherichia coli on d 4, 42, and 77 after initiation of treatments. Treatments included breed (Holstein vs. Jersey) and plane of nutrition (low vs. high). Treatment, $P<0.04$; sliced breed $\times$ plane of nutrition $(\mathrm{B} \times \mathrm{PN})$ contrast (Holstein-Low and Jersey-High vs. Holstein-High and Jersey-Low) at d 77, $P<0.01$. (b) Killing capacity of whole blood when incubated for $60 \mathrm{~min}$ against an enteropathogenic Escherichia coli on $\mathrm{d} 4,42$, and 77 after initiation of treatments. Treatment $\times$ time, $P<0.01$; sliced breed $\times$ plane of nutrition $(\mathrm{B} \times \mathrm{PN})$ contrast (Holstein-Low and Jersey-High vs. Holstein-High and Jersey-Low) at d 77, $P<0.04$. Error bars represent \pm SEM.

munoglobulins based on a cut-off point of total serum protein of $5.2 \mathrm{~g} / \mathrm{dL}$ (Tyler et al., 1996). Previous data reported a greater absorption efficiency of $\mathrm{IgG}$ and increased plasma concentrations of IgG among Jersey calves compared with Holstein calves (Tennant et al., 1969; Quigley et al., 1998; Jones et al., 2004). In addition, colostrum from Jersey cows contains a greater concentration of total $\mathrm{IgG}$ than colostrum from Holstein cows (Quigley et al., 1994). Therefore, the greater total serum protein observed among Jersey calves in the present study may reflect a real difference between Jersey and Holstein calves. Plane of MR nutrition did not influence fecal scores in the current study. This is in contrast to data from Nonnecke et al. (2003), where Holstein calves fed higher planes of MR nutrition had softer feces, which was attributed to the higher volume of water and feed consumed by those calves.

Calves are highly susceptible to bacteremia and septicemia during the first week of life (Fecteau et al., 1997; Lofstedt et al., 1999). On d 7 after initiation of treatments, all calves were challenged subcutaneously with LPS to evaluate the influence of breed and plane of MR nutrition on clinical and biochemical acute phase responses in vivo. Calves fed the higher planes of MR nutrition had greater plasma concentrations of the acute phase protein haptoglobin at $24 \mathrm{~h}$ after LPS challenge. No additional interactions were observed among treatments and time among the other clinical or biochemical responses following the LPS challenge. Furthermore, when peripheral blood mononuclear cells were isolated and stimulated ex vivo with LPS on d 42 and 77, plane of MR nutrition did not influence the secretion of the proinflammatory cytokine TNF- $\alpha$. These data suggest that plane of MR nutrition, 38 and $47.6 \%$ difference in energy and protein intakes among Holstein calves, and 24 and $33.7 \%$ difference in energy and protein intakes among Jersey calves fed the lower and higher planes of MR nutrition, has limited, if any, influence on the acute phase response of dairy calves. In contrast, Nonnecke et al. (2003) reported that isolated peripheral blood mononuclear cells from Holstein calves fed a higher plane of MR secreted more nitrite than calves fed a low plane of MR. In agreement with the results of Nonnecke et al. (2003), data from rodents and beef steers indicated that restricted energy intake attenuated the response of macrophages and peripheral blood mononuclear cells to LPS. Rats fed a $50 \%$ restricted energy diet had reduced secretion of TNF- $\alpha$ when macrophages were stimulated with LPS (Walrand et al., 2000). Furthermore, peritoneal macrophages from mice fed a $40 \%$ energy restricted diet secreted less TNF- $\alpha$ when stimulated with LPS (Sun et al., 2001). Finally, data in beef steers indicate that steers fed lower energy diets (33.6\% less $\mathrm{NE}_{\mathrm{G}}$ intake) either through increased roughage or restriction of feed offered during the receiving period had lower concentrations of TNF- $\alpha$ secreted when peripheral blood mononuclear cells were cocultured with LPS (Schwertner et al., 2011). The present data do not support the hypothesis that the proinflammatory response of pre- and immediately postweaned dairy calves is influenced by plane of MR nutrition; however, more research is needed before de- 
finitive conclusions can be determined because of the paucity of data among preweaned dairy calves.

Holsteins fed the higher plane of MR nutrition had greater concentrations of total leukocytes throughout the challenge period. This was not observed among the Jersey calves fed a higher plane of MR nutrition. The greater leukocyte concentrations in peripheral circulation observed could be due to stimulated leukopoiesis through either nutritional modulation or immunogenic stimulation. The current data from Holsteins do not agree with those of Griebel et al. (1987) and Nonnecke et al. (2003), where feeding varying planes of MR nutrition did not influence the total concentration of leukocytes in peripheral circulation in calves. However, in agreement with the current data, even mild calorie restriction in mice decreased total leukocyte counts (Cano et al., 2009). Both Holstein calves and calves fed higher planes of MR nutrition had increased plasma glucose concentrations. The greater concentrations of plasma glucose among calves fed higher planes of MR nutrition was reported previously (Foote et al., 2007). Leukocytes primarily utilize glucose and glutamine as energy sources; therefore, a greater availability of glucose among Holstein calves and calves fed the higher plane of MR nutrition could conceivably improve leukocyte function (Pithon-Curi et al., 2004). However, the immunological responses at $\mathrm{d} 4$ and the clinical and biochemical responses to the LPS challenge at $d 7$ in the current study do not support that hypothesis.

An effect of breed was observed on the secretion of TNF- $\alpha$ on $d 77$ when peripheral blood mononuclear cells were stimulated with LPS: Jersey calves had reduced concentrations of TNF- $\alpha$ compared with Holstein calves. Secretion of proinflammatory cytokines and chemokines by tissue resident leukocytes, including macrophages, is required for the recruitment and activation of large numbers of leukocytes with effector functions to sites of infection. Data indicate that a reduced latency and increased intensity of the inflammatory response can improve the recovery from mastitic infections in dairy cattle (Burvenich et al., 2003; Kauf et al., 2007); however, an uncontrolled or excessive inflammatory response can cause death (Ballou et al., 2008). It is unknown whether the observed differences in LPS sensitivity between Holstein and Jersey calves in the current study would influence resistance to enteric or pulmonary disease commonly observed in dairy calves during this period of life. This area warrants further research. Data from lactating Holstein and Jersey cows showed that there was a conserved innate immune response across breeds to an intramammary infection with either E. coli or Staphylococcus aureus (Bannerman et al., 2008a,b). Minor differences were observed in the temporal response between breeds when cows were challenged with the E. coli, whereas Jersey cows had reduced milk TNF- $\alpha$ concentration at 12 and 18 $\mathrm{h}$ postchallenge (Bannerman et al., 2008a). However, in both studies by Bannerman et al. (2008a,b), no differences were observed in the mammary clearance of the pathogens. Therefore, the current data and those from Bannerman et al. (2008a,b) do not support the hypothesis that Jersey calves have a more aggressive proinflammatory response. In fact, the current data support the opposite: Jersey calves may have a reduced sensitivity to the proinflammatory pathogen-associated molecular pattern, LPS, and this breed difference may only manifest itself after the preweaned period.

In addition to a reduced secretion of TNF- $\alpha$, Jersey calves had reduced neutrophil oxidative burst and killed fewer $E$. coli than Holstein calves when whole blood was cocultured with $E$. coli for $10 \mathrm{~min}$. These data indicate that Jersey calves have an impaired rate of response to E. coli compared with Holstein calves. Passive transfer of maternal immunoglobulins in colostrum likely did not play a factor in the reduced phagocytic and bactericidal activity of Jersey calf blood because Jersey calves actually had higher concentrations of total serum protein at enrollment. In addition, the breed effect was observed only after the neonatal period, when passively derived immunoglobulins are depleted. The significance of the lower rate of neutrophil oxidative burst and whole-blood killing capacity observed in Jersey calves with respect to resistance to disease is unknown. Previous research reported reduced whole-blood killing of gram-negative bacteria including E. coli and Salmonella typhimurium during the peripartum period, which corresponds with the well-known decrease in resistance to infectious disease (Ballou et al., 2009). In that same study, calf whole-blood killing of E. coli and Salmonella typhimurium increased over the first $21 \mathrm{~d}$ of life (Ballou et al., 2009). It is also well accepted that susceptibility to enteric infection by gram-negative bacteria is inversely related to the age of the calf (Roy, 1990). As discussed previously, the latency and intensity of neutrophil recruitment to the mammary gland following an intramammary bacterial challenge influenced the growth and subsequent clearance of the pathogen (Burvenich et al., 2003; Kauf et al., 2007). Therefore, it is conceivable that the lower rate of innate immune responses observed among Jersey calves in the current study may increase the relative risk of developing enteric or systemic disease. The current data support the hypothesis that Jersey calves have reduced neutrophil and whole-blood bactericidal capacities when compared with Holstein calves, but only after the neonatal period.

Higher planes of MR nutrition within each breed increased the intensity of neutrophil oxidative burst responses at d 77 when blood was co-incubated with 
E. coli for $10 \mathrm{~min}$. However, most of the effect of feeding a higher plane of MR nutrition during the postweaned period (d 77) was observed only among Jersey calves. Both neutrophil oxidative burst intensity and whole-blood bactericidal capacity (when co-incubated with the E. coli for $60 \mathrm{~min}$ ) of Jersey-Low calves was reduced at $\mathrm{d} 77$. The reduced neutrophil oxidative burst and whole-blood killing taken together indicate that Jersey-Low calves had reduced postweaned innate immune responses. Future research should use infection challenge models that reflect spontaneous disease to ascertain the influence of the observed differences in the innate immune responses on resistance to disease. These data partially support the hypothesis that higher planes of MR nutrition improve innate immune responses; however, most of the influence appears to be during the postweaned period and limited to Jersey calves. Explanations for a discrepancy between breeds and why Jersey-Low calves had reduced postweaned innate immune responses are lacking. In the present study, Holstein-High and Jersey-High calves were fed MR with different chemical compositions; therefore, the contribution that the composition of the higher plane of MR nutrition played in the improved innate immune responses among Jersey calves cannot be determined. Feeding higher planes of MR to Holstein calves (Barlett et al., 2006) and feeding a higher fat MR to Jersey calves (Bascom et al., 2007) both increased the percentage of body fat. It is conceivable that a greater percentage of body fat among calves fed higher planes of nutrition, and furthermore among the Jersey-High calves because they were fed a higher fat MR, increased body fat percentage. A greater percentage of body fat could increase plasma concentrations of leptin, which has been shown to increase both phagocytosis and production of proinflammatory cytokines in rodent models (Loffreda et al., 1998). More research is needed regarding how the composition of MR may influence the immune responses of calves and consequently health, especially given that increasing the fat concentrations in MR is often associated with decreased performance (Kuehn et al., 1994; Hill et al., 2009).

It should be noted that most of the improvements in the innate immune responses among Jersey calves were observed at d 77, during the postweaned period, when all calves were consuming a uniform calf starter at similar intakes across the different planes of MR nutrition. In fact, during the postweaned period, because calves previously fed the lower planes of MR nutrition had lesser BW, the intakes of both ME and CP when expressed per kilogram of metabolic BW were greater for calves previously fed the lower plane of MR nutrition. Therefore, the present data from Jersey calves contrast with recent data reported by Sakkas et al. (In press), which indicated that feeding more MP from soybeans improved the immune defense to a parasitic infection. It cannot be ruled out that a preprogramming effect existed among Jersey calves, where plane of MR nutrition during the preweaned period carried over into the immediate postweaned period. This area warrants further research.

T-Lymphocytes are critical in directing the adaptive immune response, which will be important upon subsequent exposures to a specific pathogen. Secretion of IFN- $\gamma$ by T lymphocytes is essential for the development of cell-mediated immune responses against intracellular pathogens. Following the co-incubation of peripheral blood mononuclear cells with T-lymphocyte mitogens, IFN- $\gamma$ concentrations in cell culture supernatant were determined. No treatment or treatment $\times$ time effects were observed on the secretion of IFN- $\gamma$. Additionally, 2 T-cell mitogens were used in the current study and no effects were observed for either phytohemagglutinin-P or concanavalin-A. This is in contrast with data from Nonnecke et al. (2003), where calves fed higher planes of MR nutrition for the first $60 \mathrm{~d}$ of life had lower secretion of IFN- $\gamma$ on d 60. In addition, Pollock et al. (1994) reported that calves fed 1,000 g of MR (as fed) had reduced serum concentrations of antigen-specific $\operatorname{IgA}$ and $\operatorname{Ig}_{2}$ following vaccination with keyhole limpet hemocyanin compared with calves fed $400 \mathrm{~g}$ of MR. In contrast, Foote et al. (2007) observed that higher planes of milk nutrition did not influence the percentages of $\mathrm{CD} 45 \mathrm{RO}+$ (memory) $\mathrm{CD}^{+} / \mathrm{CD}^{+} \mathrm{T}$ lymphocytes or antigen-induced IFN- $\gamma$ secretion. The current data support the idea that plane of MR nutrition during the preweaned period does not influence adaptive immune responses.

\section{CONCLUSIONS}

Neither breed nor plane of MR nutrition greatly influenced the in vivo acute phase response to LPS on $\mathrm{d} 7$ after initiation of treatments. In contrast, Jersey calves secreted less TNF- $\alpha$ ex vivo on d 77 when stimulated with LPS. In addition, whole-blood bactericidal activities of postweaned Jersey calves were less than that observed for Holstein calves. Thus, Jersey calves may be at increased relative risk for morbidity during the immediate postweaned period compared with Holstein calves. Plane of MR nutrition increased the postweaned rate of neutrophil oxidative burst intensity, irrespective of breed. However, most of the observed effects of planes of MR nutrition were restricted to postweaned Jersey calves. A higher plane of MR nutrition among Jersey calves increased the postweaned maximal oxida- 
tive burst and whole-blood killing responses compared with Jersey calves fed the lower plane of MR nutrition. These data indicate that feeding a higher plane of MR nutrition may improve postweaned resistance to disease, but the effect may be limited to Jersey calves that are already at increased risk of disease.

\section{ACKNOWLEDGMENTS}

The author thanks Clayton and Colton Cobb of Texas Tech University (Lubbock) for their assistance with animal husbandry and Lindsey Hulbert of Texas Tech University (Lubbock) for her assistance with laboratory work. The author also acknowledges the milk replacer donations and feeding recommendations made by Land O'Lakes Animal Milk Products Co. (Shoreview, MN).

\section{REFERENCES}

Ballou, M. A., G. D. Cruz, W. Pittroff, D. H. Keisler, and E. J. DePeters. 2008. Modifying the acute phase response of Jersey calves by supplementing milk replacer with omega-3 fatty acids from fish oil. J. Dairy Sci. 91:3478-3487.

Ballou, M. A., and E. J. DePeters. 2008. Supplementing milk replacer with fatty acids from fish oil on immunocompetence and health of Jersey calves. J. Dairy Sci. 91:3488-3500.

Ballou, M. A., R. C. Gomes, and E. J. DePeters. 2009. Supplemental fish oil does not alter immune competence or the pathophysiological response to an intramammary infusion of endotoxin in peripartum multiparous Holstein cows. J. Dairy Res. 76:165-172.

Bannerman, D. D., A. C. W. Kauf, M. J. Paape, H. R. Springer, and J. P. Goff. 2008a. Comparison of Holstein and Jersey innate immune responses to Escherichia coli intramammary infection. J. Dairy Sci. 91:2225-2235.

Bannerman, D. D., H. R. Springer, M. J. Paape, A. C. W. Kauf, and J. P. Goff. 2008b. Evaluation of breed-dependent differences in the innate immune responses of Holstein and Jersey cows to Staphylococcus aureus intramammary infection. J. Dairy Res. 75:291-301.

Bartlett, K. S., F. K. McKeith, M. J. VandeHaar, G. E. Dahl, and J. K. Drackley. 2006. Growth and body composition of dairy calves fed milk replacers containing different amounts of protein at two feeding rates. J. Anim. Sci. 84:1454-1467.

Bascom, S. A., R. E. James, M. L. McGilliard, and M. Van Amburgh. 2007. Influence of dietary fat and protein on body composition of Jersey bull calves. J. Dairy Sci. 90:5600-5609.

Bascom, S. S. 2002. Jersey calf management, mortality, and body composition. PhD Diss. Virginia Tech, Blacksburg.

Brown, E. G., M. J. VandeHaar, K. M. Daniels, J. S. Liesman, L. T. Chapin, J. W. Forrest, R. M. Akers, R. E. Pearson, and M. S. Weber Nielsen. 2005. Effect of increasing energy and protein intake on mammary development in heifer calves. J. Dairy Sci. 88:595-603.

Burvenich, C., V. Fan Merris, J. Mehrzad, A. Diez-Fraile, and L. Duchateau. 2003. Severity of E. coli mastitis is mainly determined by cow factors. Vet. Res. 34:521-564.

Cano, M. P. G., C. Van Nieuwenhove, Z. Chaila, G. Bazán, and S. González. 2009. Effects of short-term mild calorie restriction diet and renutrition with ruminant milks on leptin levels and other metabolic parameters in mice. Nutrition 25:322-329.

Deluyker, H. A., P. Rossitto, S. N. Van Oye, and J. S. Cullor. 2004. Efficacy of an Escherichia coli J-5 mutant strain bacterin in the protection of calves from endotoxin disease caused by subcutaneous challenge with endotoxins from Escherichia coli. Vaccine 23:709-717.
Drackley, J. K. 2008. Calf nutrition from birth to breeding. Vet. Clin. North Am. Food Anim. Pract. 24:55-86.

Fecteau, G., JParé, D. C., B. P. Van Metre, C. A. Smith, W. Holmberg, Guterbock, and S. Jang. 1997. Use of a clinical sepsis score for predicting bacteremia in neonatal dairy calves on a calf rearing farm. Can. Vet. J. 38:101-104.

Foote, M. R., B. J. Nonnecke, D. C. Beitz, and W. R. Waters. 2007. High growth rate fails to enhance adaptive immune responses of neonatal calves and is associated with reduced lymphocyte viability. J. Dairy Sci. 90:404-417.

Foote, M. R., B. J. Nonnecke, M. A. Fowler, B. L. Miller, D. C. Beitz, and W. R. Waters. 2005. Effects of age and nutrition on expression of CD25, CD44, and L-selectin (CD62L) on T-cells from neonatal calves. J. Dairy Sci. 88:2718-2729.

Griebel, P. J., M. Schoonderwoerd, and L. A. Babiuk. 1987. Ontogeny of the immune response: Effect of protein energy malnutrition in neonatal calves. Can. J. Vet. Res. 51:428-435.

Hill, T. M., H. G. Bateman 2nd, J. M. Aldrich, and R. L. Schlotterbeck. 2009. Effects of fat concentration of a high-protein milk replacer on calf performance. J. Dairy Sci. 92:5147-5153.

Hulbert, L. E., C. J. Cobb, J. A. Carroll, and M. A. Ballou. 2011. The effects of early weaning on innate immune responses of Holstein calves. J. Dairy Sci. 94:2545-2556.

Hüsier, B. R., and J. W. Blum. 2002. Metabolic and endocrine changes in response to endotoxin administration with or without oral arginine supplementation. J. Dairy Sci. 85:1927-1935.

Jones, C. M., R. E. James, J. D. Quigley III, and M. L. McGilliard. 2004. Influence of pooled colostrum or colostrum replacement on IgG and evaluation of animal plasma in milk replacer. J. Dairy Sci. 87:1806-1814.

Kauf, A. C., B. T. Vinyard, and D. D. Bannerman. 2007. Effects of intramammary infusion of bacterial lipopolysaccharide on experimentally induced Staphylococcus aureus intramammary infection. Res. Vet. Sci. 82:39-46.

Kuehn, C. S., D. E. Otterby, J. G. Linn, W. G. Olson, H. ChesterJones, G. D. Marx, and J. A. Barmore. 1994. The effect of dietary energy concentration on calf performance. J. Dairy Sci. $77: 2621-2629$

Larson, L. L., F. G. Owen, J. L. Albright, R. D. Appleman, R. C. Lamb, and L. D. Muller. 1977. Guidelines toward more uniformity in measuring and reporting calf experimental data. J. Dairy Sci. 60:989-991.

Loffreda, S., S. Q. Yang, H. Z. Lin, C. L. Karp, M. L. Brengman, D. J. Wang, A. S. Klein, G. B. Bulkley, C. Bao, P. W. Noble, M. D. Lane, and A. M. Diehl. 1998. Leptin regulates proinflammatory immune responses. FASEB J. 12:57-65.

Lofstedt, J., I. R. Dohoo, and G. Duizer. 1999. Model to predict septicemia in diarrheic calves. J. Vet. Intern. Med. 13:81-88.

Makimura, S., and N. Suzuki. 1982. Quantitative determination of bovine serum haptoglobin and its elevation in some inflammatory diseases. Nihon Juigaku Zasshi 44:15-21.

National Animal Health Monitoring System. 2007. Heifer calf health and management practices in the United States. United States Department of Agriculture: Animal and Plant Health Inspection Service: Veterinary Services (USDA:APHIS:VS), Ft. Collins, CO.

Nonnecke, B. J., M. R. Foote, J. M. Smith, B. A. Pesch, and M. E. Van Amburgh. 2003. Composition and functional capacity of blood mononuclear leukocyte populations from neonatal calves on standard and intensified milk replacer diets. J. Dairy Sci. $86: 3592-3604$.

NRC. 2001. Nutrient Requirements of Dairy Cattle. 7th rev. ed. Natl. Acad. Sci., Washington, DC.

Pithon-Curi, T. C., M. P. De Melo, and R. Curi. 2004. Glucose and glutamine utilization by rat lymphocytes, monocytes, and neutrophils in culture: A comparative study. Cell Biochem. Funct. $22: 321-326$.

Pollock, J. M., T. G. Rowan, J. B. Dixon, and S. D. Carter. 1994. Level of nutrition and age at weaning: Effects on humoral immunity in young calves. Br. J. Nutr. 71:239-248. 
Quigley, J. D. III, J. J. Drewry, and K. R. Martin. 1998. Estimation of plasma volume in Holstein and Jersey calves. J. Dairy Sci. 81:1308-1312.

Quigley, J. D. III, K. R. Martin, H. H. Dowlen, L. B. Wallis, and K. Lamar. 1994. Immunoglobulin concentration, specific gravity, and nitrogen fractions of colostrum from Jersey cattle. J. Dairy Sci. $77: 264-269$.

Roy, J. H. B. 1990. The Calf. Vol. 1. Management of Health. 5th ed. Butterworth Publishers Inc., Boston, MA.

Sakkas, P., J. G. Houdijk, S. Athanasiadou, and I. Kyriazakis. Sensitivity of periparturient breakdown of immunity to parasites to dietary protein. J. Anim. Sci. In press. http://dx.doi.org/10.2527/ jas.2011-4829.

Schwertner, L. R., L. E. Hulbert, J. A. Carroll, M. L. Galyean, and M. A. Ballou. 2011. Effects of dietary source and intake of energy on immune competence and the response to an infectious bovine rhinotracheitis virus (IBRV) challenge in cattle. Livest. Sci. 141:259-266.
Smits, E., C. Burvenich, and R. Heyneman. 1997. Simultaneous flow cytometric measurement of phagocytic and oxidative burst activity of polymorphonuclear leukocytes in whole bovine blood. Vet. Immunol. Immunopathol. 56:259-269.

Sun, D., A. R. Muthukumar, R. A. Lawrence, and G. Fernandes. 2001 Effects of calorie restriction on polymicrobial peritonitis induced by cecum ligation and puncture in young C57BL/6 mice. Clin. Diagn. Lab. Immunol. 8:1003-1011.

Tennant, B., D. Harrold, M. Reina-Guerra, and R. C. Laben. 1969 Neonatal alterations in serum gamma globulin levels of Jersey and Holstein-Friesian calves. Am. J. Vet. Res. 30:345-354.

Tyler, J. W., D. D. Hancock, S. M. Parish, D. E. Rea, T. E. Besser, S. G. Sanders, and L. K. Wilson. 1996. Evaluation of 3 assays for failure of passive transfer in calves. J. Vet. Intern. Med. 10:304-307. Walrand, S., C. Chambon-Savanovitch, C. Felgines, J. Chassagne, F. Raul, B. Normand, M. C. Farges, B. Beaufrère, M. P. Vasson, and L. Cynober. 2000. Aging: A barrier to renutrition? Nutritional and immunologic evidence in rats. Am. J. Clin. Nutr. 72:816-824. 